\title{
Chronic Elevation of Secreted Amyloid Precursor Protein in Subcortically Lesioned Rats, and Its Exacerbation in Aged Rats
}

\author{
William C. Wallace, ${ }^{1}$ Ivan Lieberburg, ${ }^{2}$ Dale Schenk, ${ }^{2}$ Carmen Vigo-Pelfrey, ${ }^{2}$ Kenneth L. Davis, ${ }^{3}$ and Vahram \\ Haroutunian $^{3}$ \\ 'Laboratory of Biochemical Genetics, NIMH, Washington, D.C., ${ }^{2}$ Athena Neurosciences, San Francisco, California, \\ and ${ }^{3}$ Department of Psychiatry, Mount Sinai School of Medicine, New York, and Bronx Veterans Administration \\ Medical Center, Bronx, New York
}

Subcortically lesioned rats were used as an animal model of some of the neurochemical and behavioral deficits of Alzheimer's disease (AD) to investigate the in vivo expression and metabolism of amyloid precursor protein (APP). Previously, the rapid and persistent induction of APP was described in cerebral cortices after disruption of its cholinergic, serotonergic, or noradrenergic afferents. In the present study, this induction was found to lead to the elevated secretion of APP into the cerebrospinal fluid of lesioned animals. Lesions of the forebrain cholinergic system in aged rats caused an even greater increase in the CSF levels of secreted APP. Antibodies to the extracellular domain of APP detected the protein whereas antibodies to the cytoplasmic region did not, indicating that the APP present in CSF was of the soluble form. Immunoprecipitation with an $A \beta$ sequence-specific antibody followed by immunoblot analysis indicated that a significant portion of secreted APP was of the species that contains at least the first 28 amino acids of the $A \beta$ sequence $\left(A P P_{\gamma}\right.$ or $\left.A P P^{A \beta}\right)$. By contrast, very low levels of $A \beta$ peptide were detected in CSF. The secretion was accompanied by an elevation of cellular C-terminal fragments of the APP in the lesioned cortex. Consistent with our previous results, this increased APP secretion was caused by lesions of subcortical cholinergic and serotonergic systems. The postlesion time course of APP secretion showed an initial reduction of APP (1 hr postlesion) in CSF followed by an eventual twofold elevation 1-6 weeks later. These results indicate that the induction of APP in response to loss of subcortical innervation leads to elevated secretion of a soluble form of cortically derived APP that contains significant portions of the $A \beta$ sequence.

[Key words: amyloid precursor protein, subcortical lesions, cholinergic system, serotonergic system, rat brain, in vivo secretion]

Two of the distinguishing neuropathological features of the AD brain are the formation of senile plaques and the dramatic reduction of the levels of specific neurotransmitters in cortical

\footnotetext{
Received Aug. 12, 1994; revised Dec. 21, 1994; accepted Jan. 10, 1995

We thank Drs. D. Selkoe, N. Robakis, and B. Wolozin for constructive comments on the manuscript; Eliot Faber and Rachel Gluck for treatment of animals and preparation of brain tissue; Natalya Grovnik for Northern blot analysis; and Donna Brane and Nancy Hsu for technical assistance on the immunobluts. This reseatch was supporled by a yramt from NIA (R01 AGI0138).

Correspondence should be addressed to William Wallace, National Institute on Aging, Gerontology Research Center, Johns Hopkins Bayview Campus, 4940 Eastern Avenue, Baltimore, MD 21224.

Copyright (C) 1995 Society for Neuroscience $0270-6474 / 95 / 154896-10 \$ 05.00 / 0$
}

regions and in the hippocampus. The primary core constituent of senile plaques is $\beta$-amyloid peptide $(A \beta)$, which is derived from a larger protein termed amyloid precursor protein (APP). Mutations of the APP gene cosegregate with $\mathrm{AD}$ in certain families (Chartier et al., 1991; Goate et al., 1991; Murrell et al., 1991; Naruse et al., 1991; Yoshioka et al., 1991; Mullan et al., 1992), implicating a central role for APP and A $\beta$ in the disease. The most prominent neurochemical deficit in $\mathrm{AD}$ is the dramatic loss of cholinergic markers in the cerebral cortex (Candy et al., 1986; Quirion, 1986; Perry, 1987), which has been attributed to the degeneration of cortically projecting cholinergic neurons in the basal forebrain (Whitehouse et al., 1982). These cholinergic deficits have been modeled in the rat by neurotoxic lesions of nucleus basalis of Meynert (nbM) (Olton and Wenk, 1987; Dekker et al., 1991). Such lesions also produce significant cognitive impairments with features common to AD (Kesner et al., 1987, 1989).

The relationship between the cellular events leading to formation of senile plaques and the neuronal alterations leading to loss of specific neurotransmitters has not been characterized. The elucidation of such a relationship will help to determine the common initial events in the pathogenesis of AD. Therefore, these two prominent neuropathological features of $\mathrm{AD}$ brain have been investigated by studying APP expression in the subcortically lesioned rat brain, which exhibits reductions of cortical neurotransmitter systems. Lesions of the nucleus basalis of Meynert (nbM) resulted in the induction of APP in the affected cerebral cortices (Wallace et al., 1991, 1993). The induction was rapid and persistent with permanent lesions, while with transient inhibition of subcortical innervation the induction was reversible. Yet, despite the long-term persistent induction of APP, lesioned rats do not exhibit cortical AD-like neuropathological structures, suggesting that the induced APP must be metabolized and/or processed in a manner that prevents and/or precludes formation of senile plaques.

These observations also suggest that APP may play a role in the response of the cortex to disrupted function-in this case, loss of subcortical innervation. In vitro experiments with cultured cells have suggested that secreted APP may act as a neuroprotectant (Mattson et al., 1993) or growth factor (Saitoh et al., 1989; Milward et al., 1992). More recently, in vivo experiments have been described which show that exogenous administration of secreted APP can protect against experimentally induced ischemic brain injury (Smith-Swintosky, 1994).

In this study, the metabolism of induced APP in the subcor- 

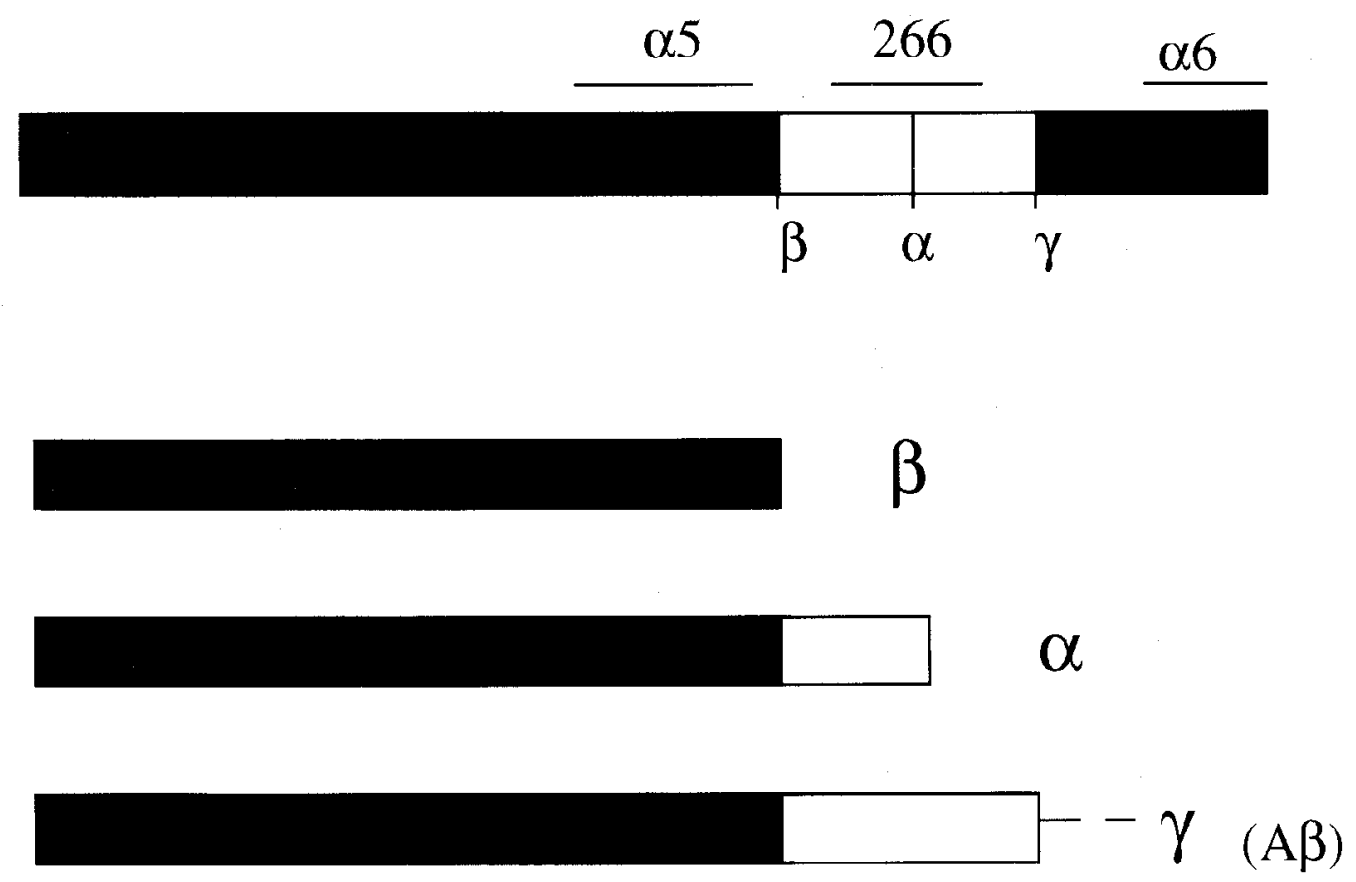

Figure 1. Schematic diagram of cellular APP (top) showing regions of molecule recognized by various antibodies and areas of cleavage by proteases. Shown below are the resulting forms of secreted APP to indicate the terms used to identify the various forms of soluble APP.

tically lesioned rat brain was characterized to explore the biological role of APP in brain function and in an attempt to determine a biochemical explanation for the absence of senile plaques. Concomitant with the induction of APP by disruption of either cholinergic or serotonergic innervation, levels of the secreted form of APP were elevated in CSF of lesioned animals. Consistent with the absence of senile playues in these animals, very low levels of $A \beta$ peptide were detected in CSF. Instead, the secreted APP product contained at least the first 28 amino acids of $A \beta$ peptide sequence ( $A P P_{\gamma}$, the form first described by Anderson et al., 1992). The elevated secretion of APP was accompanied by elevated amounts of cellular APP C-terminal derivatives in the cortex. These observations of the induction and secretion of APP, taken together with the results of cultured cell studies, suggest a biological role for APP in response to a specific disruption of brain function that is relevant to the pathogenesis of $A D$. Further, the low levels of $A \beta$ peptide in rat $C S F$ suggest that the persistently secreted APP in the lesioned rat was metabolized with a nonpathological proteolytic cleavage, thus possibly accounting for the absence of senile plaques in these animals. However, the presence of the initial 28 amino acid residues of the $A \beta$ peptide, which have been shown to be sufficient for neurotoxicity in rat (Yankner et al., 1990), suggests that the APP which is secreted in response to subcortical neurotransmitter system lesions may have the potential for neurotoxicity.

\section{Materials and Methods}

Three specific experiments were performed. In the first, different groups of young adult rats received either stereotaxic lesions of the nbM or sham operations. One hour or 1 week later each rat was anesthetized and a CSF sample was collected for the assay of secreted APP. After death, the cerebral cortices were dissected and frozen on dry ice for cholinergic marker assay to quantify the magnitude of the lesion and for immunoblot analysis of various APP fragments. In the second experiment, the same procedures were followed but the rats were killed at different time points after lesioniug to investigate the time course of lesion-induced changes in secreted APP. In addition, a separate group of animals was treated identically but received lesions of the serotonergic system instead in order to determine the generality of the lesion effects on APP levels in CSF. In the third experiment, similar lesions of the nbM were performed on young ( 2 months) and aged ( 24 months) F344 rats to determine the effect of age on the induction of cortical APP following the lesion.

Placement of subcortical lesions. Animals were treated under the same conditions that resulted in the induction of APP synthesis as described previously (Wallace et al,, 1991, 1993). For forebrain cholinergic system lesions, adult male Sprague-Dawley rats ( 8 weeks old) received unilateral subcortical lesions of the nucleus basalis of Meynert (nbM) using $N$-methyl-D-aspartate (NMDA) as the excitotoxin. All rats were anesthetized with $45 \mathrm{mg} / \mathrm{kg}$ pentobarbital and placed within a stercotaxic apparatus with the upper incisor bar set level with the intraaural line. A 33 gauge infusion cannula was lowered into two sites within the nbM on one side of the brain (AP bregma, ML -2.8 , DV -8.0 re skull; AP bregma -0.8 , ML -3.0 , DV -7.8 , respectively). One microliter of a $50 \mathrm{~mm}$ solution of NMDA in PBS was slowly infused into each site. Controls for the lesion were the contralateral cortices of the same animals. For lesions of the forebrain serotonergic system, the dorsal raphe nucleus (DRN) was lesioned by the slow infusion of a $1 \mu \mathrm{l}$ solution of $15 \mu \mathrm{g} / \mu \mathrm{l} 5,7$-dihydroxytryptamine at stereotaxic coordinates AP IAL $+1.5, \mathrm{ML}-4.5, \mathrm{DV}-7.0$ re skull, angle $24^{\circ}$ from vertical. All rats were pretreated with $20 \mathrm{mg} / \mathrm{kg}$ desmethylimipramine $30 \mathrm{~min}$ prior to lesioning. Because the DRN is a midline structure, a separate group of sham-lesioned animals were prepared as controls. These animals received the same treatments as the lesioned rats except that the neurotoxin was not infused into the DRN.

Collection of CSF and cortical tissue. Immediately prior to death, each rat was anesthetized with $45 \mathrm{mg} / \mathrm{kg}$ pentobarbital and placed in a stereotaxic frame. The occipital foramen was exposed by blunt dissection and a 22 gauge cannula attached to PE10 tubing was inserted into the cisterna magna. CSF $(100-150 \mu \mathrm{l})$ was collected in a $2 \mathrm{~m}$ length of PE10 tubing. The CSF was frozen on dry ice and kept at $-80^{\circ}$ until assayed. Each rat was then decapitated, the brain was quickly extracted, and the right and left cortices were dissected over ice and frozen at $-80^{\circ}$. Separate aliquots of CSF from each rat were used for immunoblot analysis and for ELISA. Each cortical sample was then pulverized and divided into two homogenous aliquots. One aliquot was used for nellrochemical determinations (choline acetyltransferase activity as described by Fonnum, 1975, and serotonin by HPLC as described by Muruyama et al., 1980). The second cortical tissue aliquot was used for immunoblot analysis. 

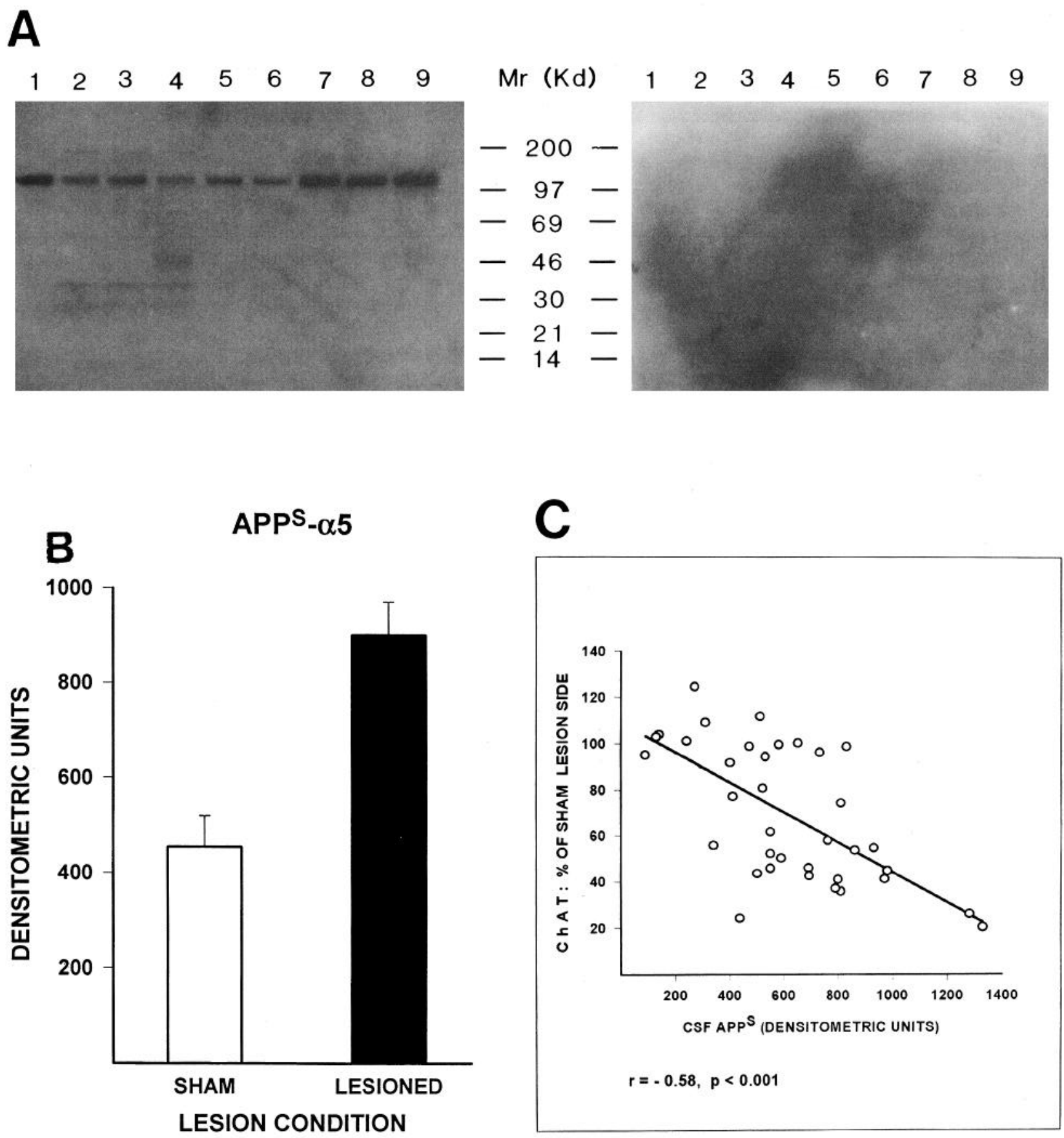

Figure 2. Elevation of secreted form of APP in CSF of animals $7 \mathrm{~d}$ after lesion of nucleus basalis of Meynert. Rats were given unilateral lesions of the nbM using NMDA as described in Materials and Methods. After either $1 \mathrm{hr}$ or $7 \mathrm{~d}$, the animals were killed. Total protein from equal aliquots $(30 \mu \mathrm{l})$ of cisternal CSF obtained at death was separated by SDS-PAGE and blotted onto PVDF paper. The blots were probed with either of two distinct antibodies to APP and detected with immunofluorescence. A, Detection of secreted extracellular domains of APP (with $\alpha 5$, left) or C-terminal cytoplasmic domains of APP $(\alpha 6$, right). Lanes 1-3 represent naive animals not lesioned; lanes 4-6 represent $1 \mathrm{hr}$ postlesion time; lanes 7-9 represent $7 \mathrm{~d}$ postlesion time. $B$, Quantitation of the secreted APP levels in CSF. APP signals on the blots were quantitated with CCD camera densitometry and the IMAGE 4.1 program. Concentration of APP is presented as arbitrary densitometry units detected on blot. * $p<0.05$ by Student's $t$ test; $n=12$. $C$, Correlation of secreted APP levels in CSF with depletion of choline acetyl transferase activity in lesioned cerebral cortex ( $p<$ $0.001 ; n=36)$.

Immunoblot analysis of CSF and cortical tissue. The second cortical tissue aliquot (approximately $100 \mathrm{mg}$ ) was used to characterize APP by immunoblot analysis. After homogenization in Tris buffer containing $2 \%$ SDS, total protein was separated by SDS-PAGE using 10-20\% Tristricine gels (Novex). The proteins were blotted onto PVDF paper and probed with antibodies to APP using immunofluorescence for visualization (ECL, Amersham). Antibody $\alpha 5$ is an affinity-purified anti-APP antibody directed to the ectodomain of APP (residues 444-590; Fig. 1).
Antibody $\alpha 6$ is a similarly purified antibody directed to the cytoplasmic domain of APP (residues 591-695; Fig. 1). The results were quantitated by densitometry using a CCD camera and the IMAGE 4.1 program.

ELISA of $A P P^{A \beta}$ in $C S F$. A rat $A \beta$ sandwich ELISA was developed using the monoclonal antibody 266 (Seubert et al., 1992) generated to residues $A \beta_{13-28}$ (Fig. 1) as a solid phase in the microtiter dish $(5.0 \mu \mathrm{g} /$ $\mathrm{ml}$ purified antibody in PBS). After blocking the plates, rat $\mathrm{A} \beta$ standards or samples were added $(0.25-2.0 \mathrm{ng} / \mathrm{ml})$, incubated for $1 \mathrm{hr}$ at $21^{\circ} \mathrm{C}$, 

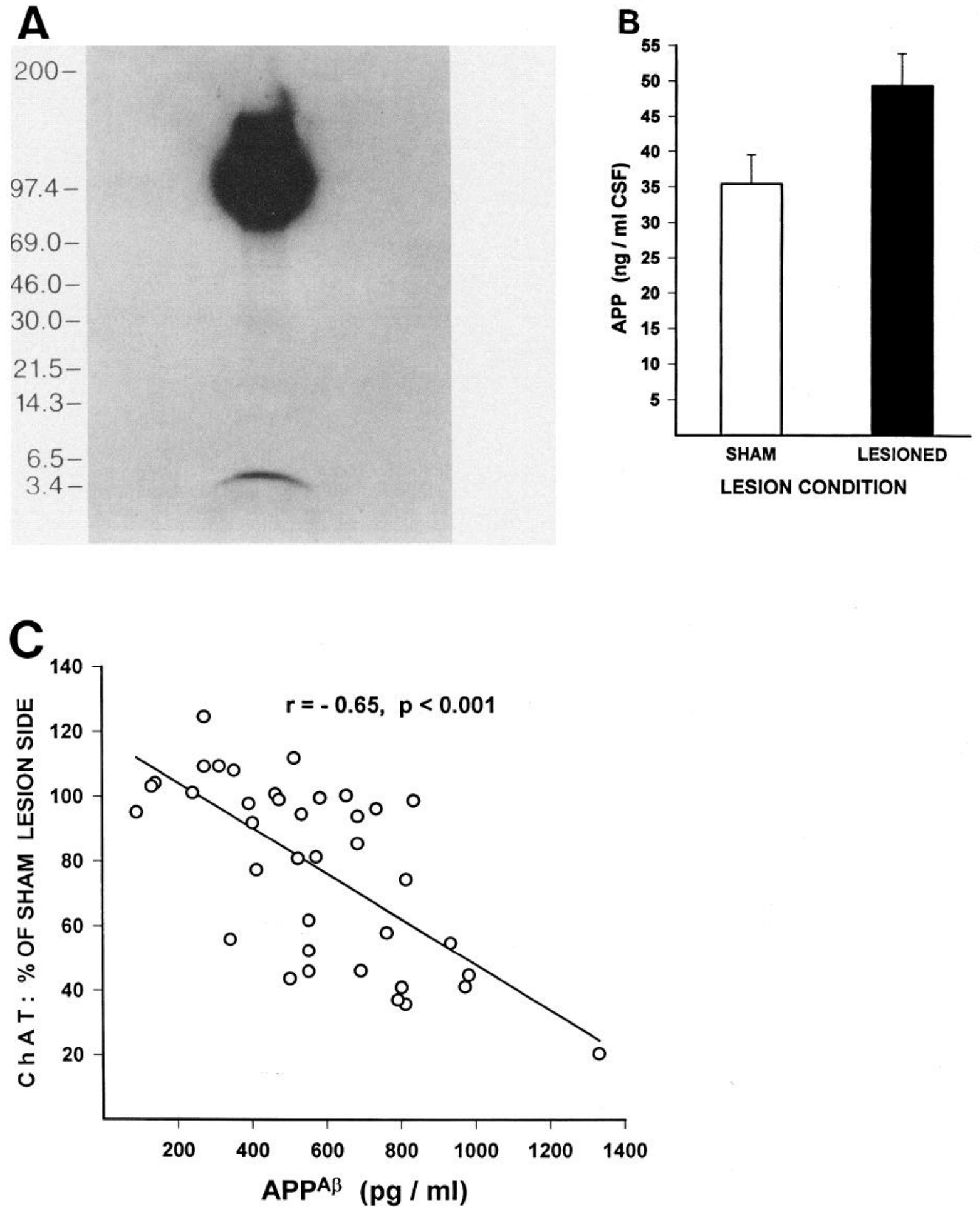

Figure 3. Characterization of $\mathrm{A} \beta$ sequence in secreted APP. A, An aliquot $(30 \mu \mathrm{l})$ of antibody 266 coupled to Actigel resin (4 mg/ml) was added to $6 \mathrm{ml}$ of rat $\mathrm{CSF}$ which contained $1.9 \mathrm{ng} / \mathrm{ml} \mathrm{A} \beta$ sequence (as determined by ELISA). The resulting mixture was nutated overnight at $4^{\circ} \mathrm{C}$. The sample was assayed by ELISA to confirm that all A $\beta$ reactivity was depleted from the CSF. The resin was collected by centrifugation and the pellet was washed twice with cold PBS. The resin was then boiled in $30 \mu \mathrm{l}$ of SDS-PAGE sample buffer and electrophoresed in a Tricine 10-20\% gradient gel. The separated proteins were blotted onto a Problot membrane, probed with a polyclonal antibody against rat $A \beta$ sequence (rat ${ }_{1-28}$ ), and the immunoreactivity visualized by immunofluorescence (ECL, Amersham). B, Elevation of APPA $\beta$ in CSF $7 \mathrm{~d}$ after lesion of the nucleus basalis of Meynert. Rats were unilaterally lesioned and cisternal CSF collected immediately prior to death $7 \mathrm{~d}$ later as described in Materials and Methods. Aliquots of CSF were assayed for APP ${ }^{\wedge} \beta$ immunoreactivity using an enzyme-linked immunosorbent assay adapted to specifically detect rat sequence of the $A \beta$ peptide. Ipsilateral and contralateral cortices from the same animals were assayed for choline acetyl transferase activity as a measure of the cortical effects of the lesion. $B$, Levels of APPA in CSF $(\mathrm{pg} / \mathrm{ml})$ for naive and $7 \mathrm{~d}$ postlesioned animals. ${ }^{*} p<0.05$ by Student's $t$ test; $n=$ 12. $C$, The concentration of APPA in CSF was plotted versus the depletion of ChAT activity (as a percentage of ipsilateral to contralateral cortex for individual samples) for each animal. The correlation coefficient indicated a significant relationship between loss of cholinergic innervation and elevation of $\mathrm{APP}^{\wedge} \beta$ in $\operatorname{CSF}(p<0.001, n=36)$. 
Figure 4. Elevation of C-terminal derivatives of APP in lesioned cortex. Rats were unilaterally lesioned as described in Materials and Methods. Ipsilateral and contralateral cortices were dissected from brain, immediately frozen, and dry homogenized. Aliquots of the tissue were assayed for choline acetyl transferase activity and APP content. APP was assayed by homogenization of tissue in a Tris buffer containing 2\% SDS with sonication. Total proteins were separated on $10-20 \%$ Tris-tricine gels, blotted, and probed with antibodies to the C-terminal domain $(\alpha 6)$. Lanes $1-4$ represent lesioned cortical homogenates from four different animals. Lanes 5-8 represent control cortical homogenates from the same four unilaterally lesioned animals.

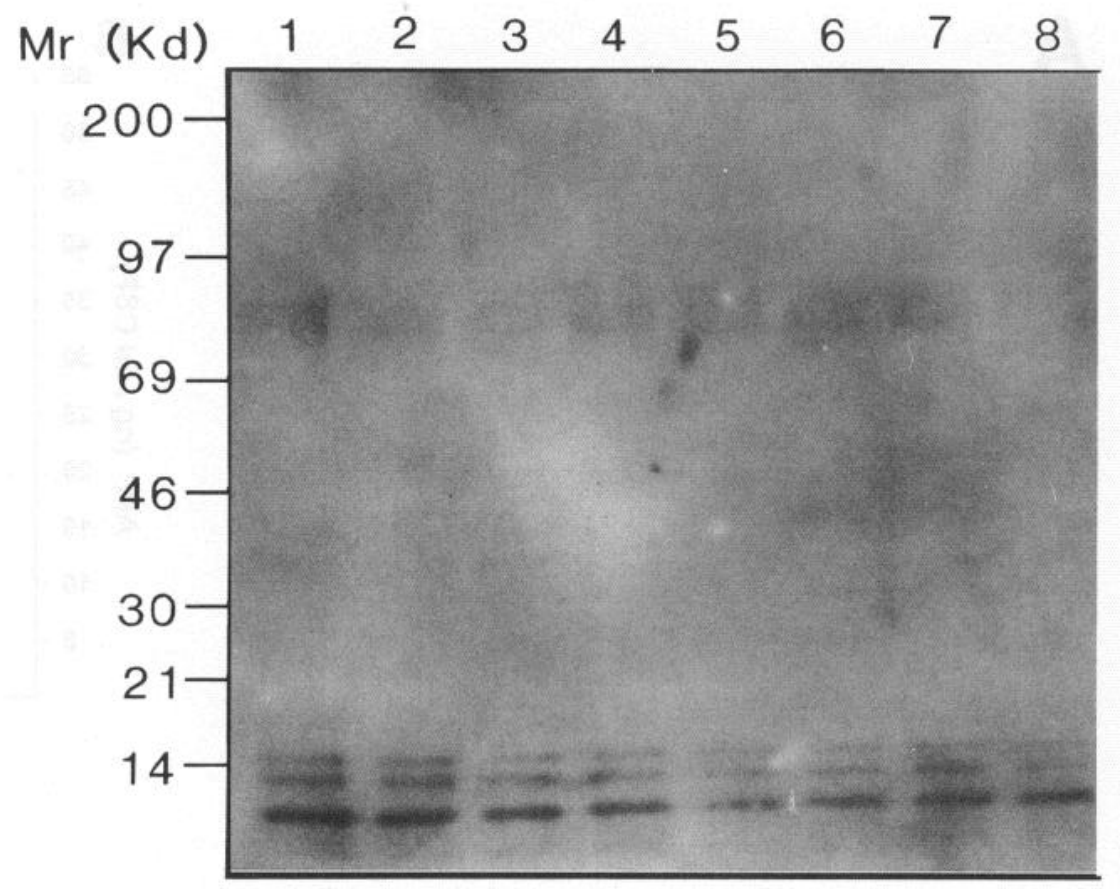

and washed. Affinity-purified rabbit anti-rat $A \beta_{1-28}$ was added, $2.0 \mu \mathrm{g} /$ $\mathrm{ml}$ in $0.1 \%$ casein, PBS for $1 \mathrm{hr}$ at $21^{\circ}$, and washed. The bound antibody complex was quantitated with alkaline phosphatase donkey anti-rabbit (1:1000) followed by the addition of substrate (methylimbelliphenyl phosphate) as described (Seubert et al., 1992).

Examination of lesion effects on young and aged animals. To determine whether age of the animal contributes to the induction and secretion of APP, different groups of young ( 2 months old; 15 lesioned and seven sham) and aged (24 months; 14 lesioned and seven sham) rats received either sham lesions or unilateral NMDA-induced lesions of the nbM using parameters identical to those described above. One week after surgery, each rat was anesthetized with pentobarbital $(65 \mathrm{mg} / \mathrm{kg})$. CSF was collected using the procedures described above and the frontal cortices were dissected, dry homogenized, aliquotted into separate samples, and frozen for subsequent assay. Aliquots of CSF were assayed for APP using $\alpha 5$ antibody as described above. Aliquots of the cortical samples were assayed for ChAT activity as described above. Total RNA was extracted from a second set of cortical aliquots (Chomczynski and Sacchi, 1987). RNA samples were analyzed with Northern blots as previously described (Wallace et al., 1993). Equal aliquots of RNA (10 $\mu \mathrm{g}$ ) were separated on $1 \%$ agarose gels and blotted onto nitrocellulose filters. Each blot was probed with a 297 base ${ }^{32} \mathrm{P}$-labeled APP riboprobe and a second 352 base ${ }^{32} \mathrm{P}$-labeled riboprobe generated for $\mathrm{N}$-protein, which has been localized specifically to neurons (Schmauss et al., 1992). The plasmid constructs were kindly provided by Dr. C. Schmauss (The Mount Sinai School of Medicine). The resulting autoradiograms were quantitated by densitometry using the mRNA band corresponding to N-protein to normalize the APP mRNA values. APP mRNA values were then compared for ipsilateral to contralateral sides of the same animal.

\section{Results}

\section{Effects of forebrain cholinergic lesions $7 d$ after lesioning}

Unilateral lesions of nbM resulted in a significant $[t(\mathrm{df} 19)=$ $14.1 ; p<0.01] 50.9 \%$ reduction of ChAT activity in the cortex ipsilateral to the lesion $7 \mathrm{~d}$ after lesioning. As predicted by earlier studies (Wallace et al., 1993), the infusion of NMDA into the nbM failed to affect cortical ChAT activity at $1 \mathrm{hr}$ postlesion.

CSF from animals that had been lesioned for $7 \mathrm{~d}$ contained significantly higher $[t(\mathrm{df} 19)=2.1 ; p<0.02]$ concentrations of APP than did CSF derived from either naive animals or $1 \mathrm{hr}$ postlesion animals (Fig. 2). The APP detected in CSF was determined to be the truncated form based upon its lack of reac- tivity with an antibody specific to the C-terminal region of the molecule ( $\alpha 6$, Fig. 2). Quantitation by densitometry indicated an approximately twofold elevation at the $7 \mathrm{~d}$ time point (Fig. 2B). Similar results were obtained using two different antibodies to the extracellular domain of APP ( $\alpha 5$ and rat $\left._{1-28}\right)$. This increased CSF content of secreted APP was correlated with depletion of cortical cholinergic innervation (as measured by cortical choline acetyl transferase activity) $7 \mathrm{~d}$ postlesion $(r=-0.58, p<0.001$; $n=36$ ) (Fig. 2C).

The $A \beta$ immunoreactivity present in the CSF of naive and lesioned animals (as seen with anti-rat ${ }_{1-28}$ ) was further characterized by immunoprecipitation. A large pool of rat CSF $(6 \mathrm{ml})$ was immunoprecipitated with rat $_{1-28}$, an antibody specific to the first 28 amino acids of rat $A \beta$ peptide. The immunoprecipitated products were visualized by immunoblot analysis with antibody 266 (generated to $A \beta_{13-28}$; Vigo-Pelfrey et al., 1993). Very little $\mathrm{A} \beta$ peptide $(4 \mathrm{kDa})$ was detected in the CSF (Fig. 3). Instead, a secreted APP species was detected, indicating that this molecule contained a significant portion of the $A \beta$ sequence. This secreted APP molecule (here termed APPA ) appears to be most similar to a form described previously in PC12 cell culture media (APP; Anderson et al., 1992), and distinctly different both from the APP which lacks the A $\beta$ sequence altogether, as described in human cells $\left(\mathrm{APP}_{\beta}\right.$; Seubert et al., 1993), and the originally described $\alpha$ secretase-cleared material which is cleaved at $A \beta_{17}\left(\mathrm{APP}_{\alpha}\right.$; Esch et al., 1990). We can conclude that the $A \beta$ sequence within the secreted APP extends to at least 28 residues based upon previous peptide competition studies that have shown that the epitopes of the monoclonal antibody 266 are amino acids $13-16$ plus $20-28$ combined of the $A \beta$ peptide (data not shown). Figure 1 schematically presents these forms of secreted APP. In order to be able to quantify APP ${ }^{\wedge}$, an enzyme-linked immunosorbent assay was then developed for AP$\mathrm{P}^{\mathrm{AB}}$ as described in Materials and Methods. The APP ${ }^{\mathrm{A} \beta}$ content in the 7-d-lesioned animals showed an elevation that was similar to that of total APP observed with immunoblots using other antibodies to the extracellular region of APP (Fig. 3B). When 
A
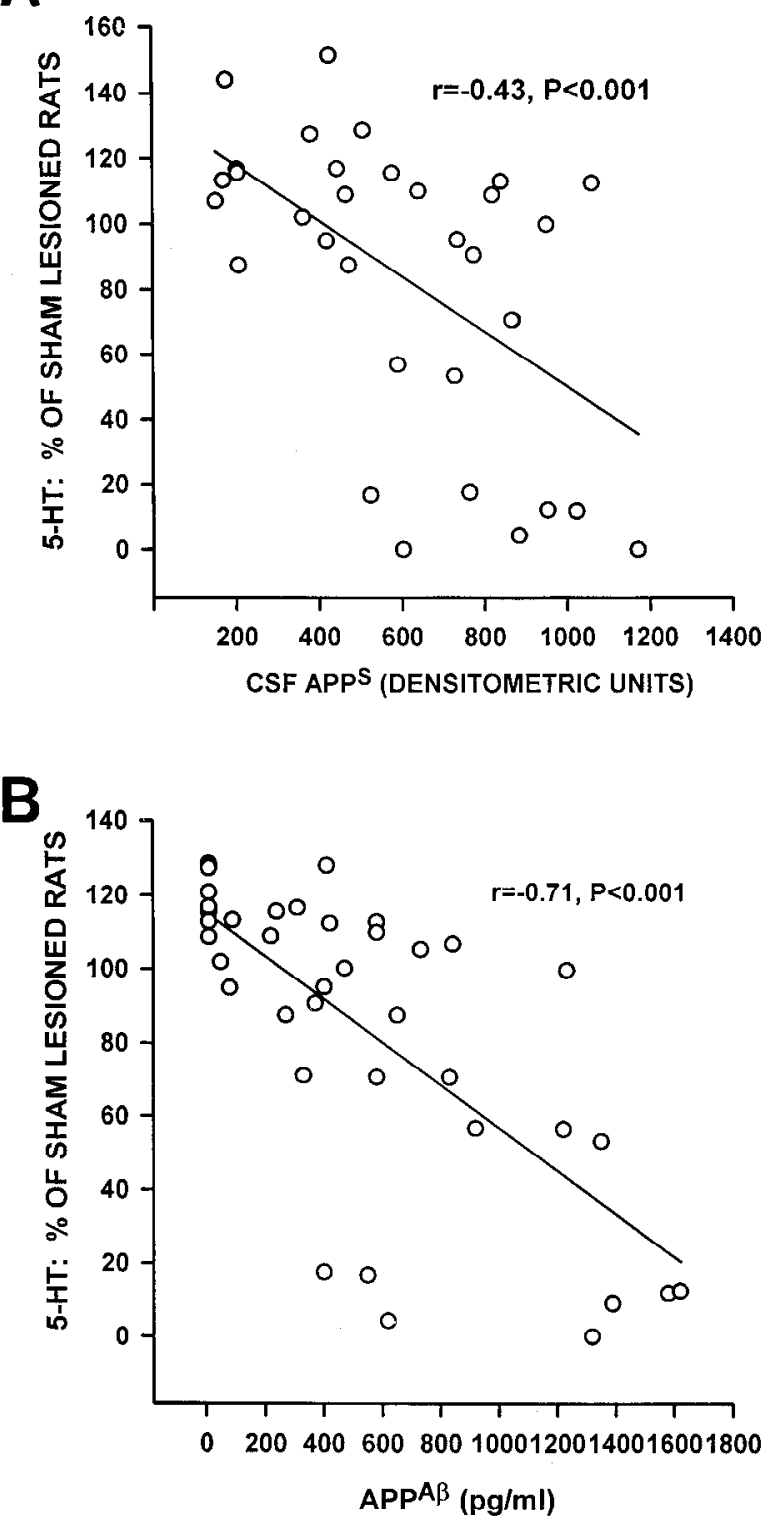

Figure 5. Elevation of APP and $\mathrm{APP}^{\wedge \beta}$ secretion with lesions of serotonergic innervation. Rats were lesioned at DRN to disrupt serotonergic innervation to cortex as described in Materials and Methods. CSF was collected $7 \mathrm{~d}$ after placement of the lesion and the levels of APP $\left(\right.$ (op) and APP ${ }^{\wedge \beta}$ (bottom) were assayed as described. The levels of both secreted APP and $A P P^{\wedge} \beta$ in CSF were similarly plotted versus depletion of cortical serotonin in animals having lesions of the dorsal raphe nucleus. 'The correlation coefficient indicated a significant relationship between loss of serotonergic innervation and elevation of both secreted $\operatorname{APP}(p<0.001 ; n=31)$ and $\operatorname{APP}^{\mathrm{A \beta}}(p<0.001 ; n=36)$.

the cortical levels of the cholinergic marker ChAT were compared with the CSF levels of $A P^{A \beta}$ in naive and lesioned animals, there was a strong correlation between the degree of cholinergic depletion in the cortex ipsilateral to the nbM lesion and the levels of $A P P^{A} \beta$ in the CSF, suggesting a close relationship between these two variables (Fig. $3 C$ ). Although the proportion of total secreted APP that is made up of $\mathrm{APP}^{\mathrm{A} \beta}$ cannot be quantitated with these experiments, the remarkable similarity of altered levels of secreted APP and $A P^{A B}$ to the various lesion conditions (compare Figs. 2, 3, 5, 6) argues that a significant fraction, if not the majority, of secreted APP is the APPAB form.
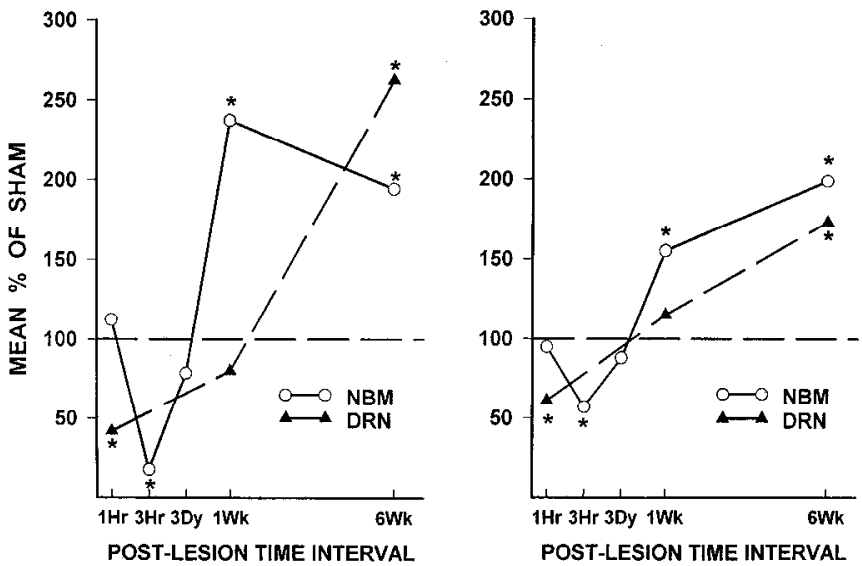

Figure 6. Time course of secreted APP (left) and $\mathrm{APP}^{\wedge \beta}$ (right) in CSF after lesions of nucleus basalis of Meynert (solid line) or dorsal raphe nucleus (dashed line). Rats were given lesions of either the nucleus basalis of Meynert or dorsal raphe nucleus as described in Materials and Methods. At various times after placement of the lesion (1 $\mathrm{hr}, 3 \mathrm{hr}, 3 \mathrm{~d}$, 1 week, and 6 weeks for nbM lesions; $1 \mathrm{hr}, 1$ week, and 6 weeks for DRN lesions), cisternal CSF was collected immediately prior to death. Concentrations of secreted APP were determined with densitometry of immunoblots as described in Materials and Methods. The results represent 5-8 animals for each data point. Concentrations of $A P P^{A B}$ in CSF were determined with ELISA as described in Materials and Methods. *Versus SHAM, $p<0.05$.

\section{Analysis of APP C-terminal fragments in cortex}

Upon secretion, a fraction of total cellular $\triangle P P$ undergoes a proteolytic cleavage in which the cytoplasmic portion of the molecule remains in the cell (Esch et al., 1990). Therefore, the C-terminal derivatives of APP in the lesioned and control cortices from the same unilaterally lesioned animals were examined using an antibody to the C-terminal region of APP $(\alpha 6)$. An elevation in the C-terminal derivatives became apparent in the 7-d-lesioned cortex (Fig. 4). Quantitation by densitometry indicated an elevation of these derivatives that was similar to the elevation of secreted APP in CSF of lesioned animals (data not shown). Although the precise identities of these derivatives are not yet known, based upon their size and antigenicity they are most likely analogous to the various C-terminal derivatives that have been characterized in cultured cells (Esch et al., 1990; Golde et al., 1992). Thus, it may be concluded that the lesioned cortex exhibits increased synthesis of APP (as shown by Northern blot analysis and polysome run-off assays; Wallace et al., 1993) which leads to the increased secretion of truncated APP containing some, if not all, of the $A \beta$ sequence (as shown by elevated levels of APP in CSF), and the generation of C-terminal derivatives in the lesioned cortex (representing the portion of the molecule that remains in the cell after secretion).

\section{Generality and time course of APP secretion after lesioning}

Previously reported studies (Wallace et al., 1991, 1993) had shown that (1) the cortical induction of APP is a response common to lesions of the forebrain cholinergic system and lesions of the DRN, which deplete cortical levels of serotonin, and (2) APP remains induced in the cortex following lesioning for at least 6 weeks. The results of the current study similarly showed that these lesions lead to the elevation of APP and APPA $\beta$ for protracted times after lesioning.

To further correlate the loss of innervation with the secretion of APP, the dorsal raphe nucleus (DRN) was lesioned, resulting 


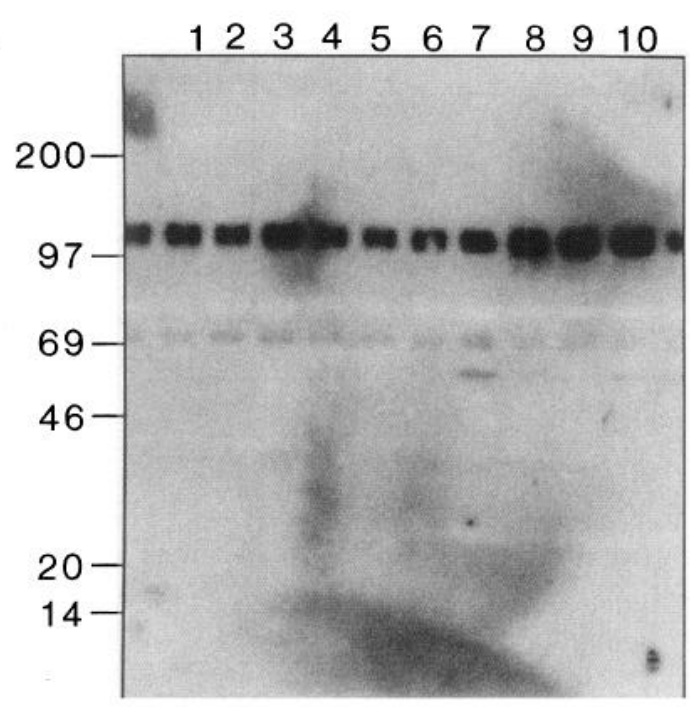

APP $^{S}-$ a5
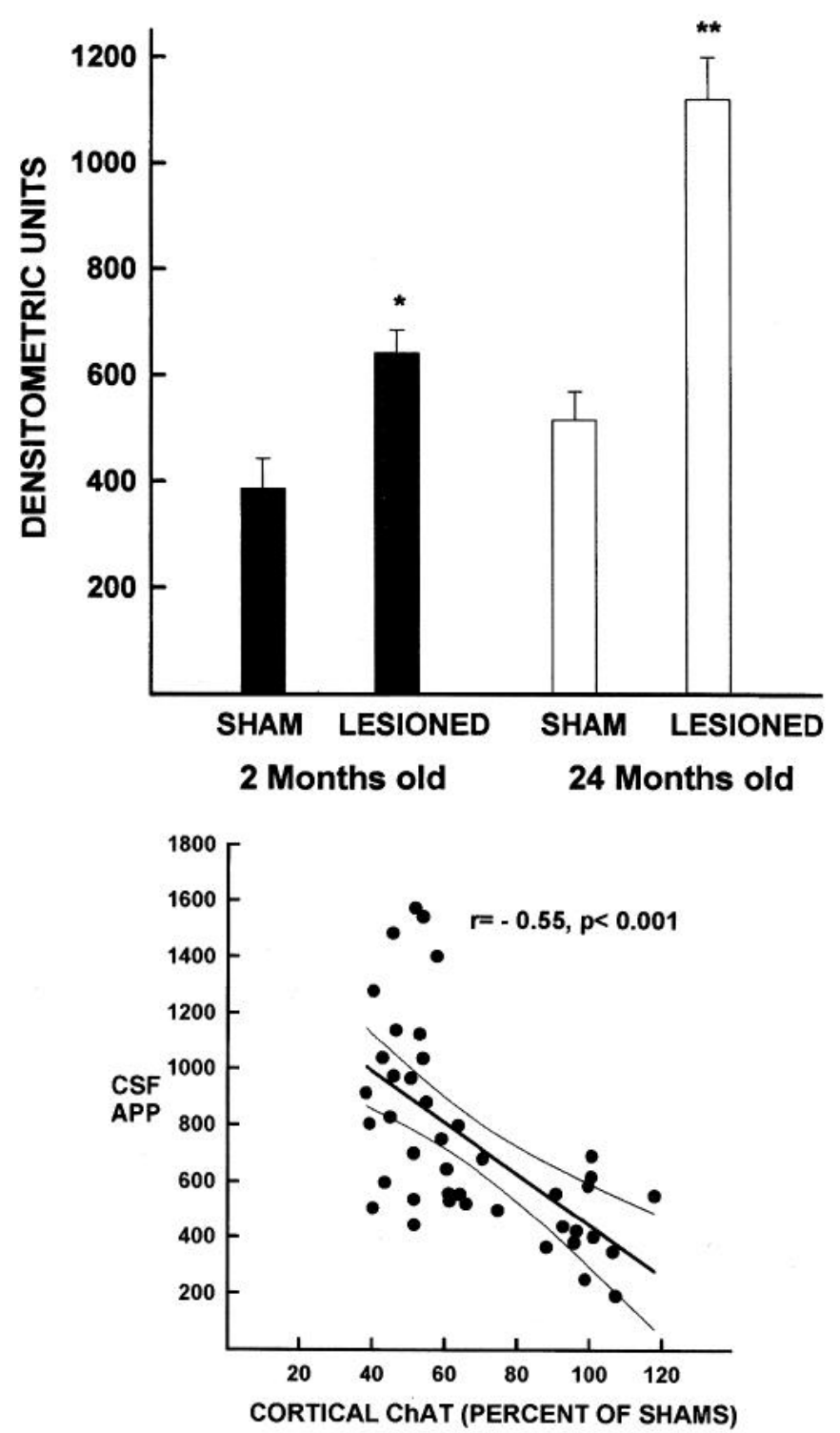

Figure 7. Greater elevation of APP secretion after lesioning in older rats ( 24 months) compared to young adult rats ( 2 months). Rats were in the disruption of the serotonergic innervation of the cortex. Such lesions also resulted in elevated levels of secreted APP in CSF as determined by both immunoblots and ELISA (Fig. 5). The samples exhibited a significant correlation between loss of serotonergic innervation and APP in CSF $(r=-0.43, p<$ $0.001 ; n=32)$ and $\mathrm{APP}^{\mathrm{A} \beta}$ in $\operatorname{CSF}(r=-0.71, p<0.001 ; n=$ $38)$.

The time course of altered CSF levels of APP was examined various times after lesions of either the nbM or DRN. Both types of lesions eventually resulted in a similar elevation of secreted APP and APP ${ }^{A \beta}$ in CSF (Fig. 6). After 6 weeks, the CSF levels of secreted APP were increased approximately twofold with the nbM lesion and 1.6-fold with the DRN lesions. The CSF levels of $\mathrm{APP}^{\mathrm{A} \beta}$ were increased approximately twofold with the nbM lesions and over 2.5-fold with the DRN lesions. Interestingly, in the most immediate times after lesioning (1-3 hr), the concentrations of APP in the CSF were significantly reduced $(p s<$ $0.01)$.

\section{The effects of age on the secretion of cortical APP after lesioning}

Chronological age is a major determinant of senile plaque formation, with the numbers of cortical senile plaques increasing as individuals age (Ball, 1977; Perry et al., 1978; Hauw et al., 1988; Mirra et al., 1991). In rats, evidence has been reported to suggest that the expression and processing of APP is altered in the nbM of aged animals and animals exhibiting reduced memory performance (Higgins et al., 1990; Beeson et al., 1994). Therefore, we examined the induction and secretion of APP in response to lesions of the nbM in 2- and 24-month-old Fisher 344 rats (Fig. 7). Analysis of the ChAT depletion caused by the lesioning showed that NMDA caused an equal reduction of cortical ChAT in young versus old rats (50-56\% lesioned vs sham; $p s<0.0001$; young lesioned vs old lesioned $p>0.5$ ). Examination of APP mRNA in the cortical tissues of the same rats demonstrated that the levels of APP mRNA were increased to $185 \%$ of control values in young animals and to $206 \%$ of control in aged rats. Analysis of variance confirmed a significant main effect of lesion condition $(F 1 / 36=16.4, p=0.00026)$ and no significant lesion condition by age interaction $(F\langle 1.0, p\rangle$ 0.5 ). Post hoc tests (Newman-Keuls) showed significant differences between lesioned and control tissues at each age $(p s<$ 0.02 ), but no significant differences between the lesion cortices at the two ages $(p=0.44)$. The levels of cortical APP mRNA correlated significantly with cortical ChAT activity $(r=-0.48$, $p=0.002$ ), suggesting that cortical APP mRNA, similar to the

\section{$\leftarrow$}

given unilateral lesions of the nbM using NMDA as described in Materials and Methods. After $7 \mathrm{~d}$, the animals were killed and CSF was obtained as described above. Total CSF protein was separated by SDSPAGE, blotted onto PVDF filter membranes, and the blot probed with $\alpha 5$ antibody and visualized by immunofluorescence. $A$, Detection of secreted APP in CSF. Lanes 1-4 represent four different 2-month-old animals; lanes 1 and 3 are lesioned rats while lanes 2 and 4 are controls (sham operated). Lanes 5-10 represent six different 24-month-old animals; lanes 5-7 are the controls (sham operated) while lanes $8-10$ are unilaterally lesioned animals. $B$, Quantitation of the secreted APP levels in CSF. APP signals on the blots were quantitated with CCD camera densitometry and the IMAGE 4.1 program. Concentration of APP is presented as arbitrary densitometry units detected on blots. ${ }^{*} p<0.05$; ${ }^{*} p$ $<0.01$ by Student's $t$ test; $n=14$. $C$, Correlation of secreted APP levels in CSF of 24-month-old rats with depletion of choline acetyl transferase activity in lesion cerebral cortex $(p<0.001, n=42)$. 
cholinergic marker depletion, was increased as a result of the nbM lcsion, but that this clcvation was not greater in the aged animals compared to the young animals.

In contrast, the levels of secreted APP in CSF were not only elevated in all lesioned rats compared to controls, but the increased concentrations of CSF APP were significantly greater in the CSF of older animals relative to the young (Fig. 7A). As shown above, nbM lesions caused a significant increase in the levels of APP in the CSF of young rats (166\% of control, $p<$ 0.03 ). Lesions of nbM caused an increase of CSF APP in aged rats, but this increase $(217 \%$ of controls vs shams $p<0.0001)$ was significantly greater than that observed in the young animals $(p<0.001$ ) (Fig. 7B). The levels of CSF APP were highly and negatively correlated with cortical ChAT activity $(r=-0.55, p$ $<0.001$; Fig. $7 C$ ). However, no significant correlation was apparent between cortical APP mRNA and CSF APP in aged animals $(r=0.28, p=0.22$ ), whereas younger lesioned animals exhibited a significant correlation $(r=0.41, p=0.011)$.

\section{Discussion}

The relationship between two of the pronounced alterations in the cortex that are associated with $\mathrm{AD}$-reduced neurotransmitter content and presence of senile plaques-was investigated using a subcortically lesioned animal model (Wallace et al., 1991, 1993). The observation that lesions resulted in the induction of APP indicated that loss of subcortical innervation affected cortical APP expression. In the present study, the induced APP was found to be secreted into the CSF (Fig. 2). The biological consequences of increased cortical APP secretion following disruption of cortical innervation is not clear. Soluble APP has been shown to have neuroprotectant activity (Smith-Swinowsky et al., 1994) and to promote neurite extension (Milward et al., 1992). The present results, which were obtained in vivo, support the hypothesis which points to a role for secreted $\Lambda P P$ in maintain ing neuron and/or synapse functional integrity in the compromised cortex.

Despite the constant elevated secretion of APP under the lesion conditions, the rat cortex does not form senile plaques even years after lesioning (Thal et al., 1990). Consistent with the absence of senile plaques, very little $A \beta$ peptide was detected in lesioned rat CSF (Fig. 3). Instead, a significant portion of the $A \beta$ sequence was detected as part of a secreted form of APP (APPA $)$. Previously, we reported that rat CSF contained low levels of $A \beta$ immunoreactivity (Seubert et al., 1992). Our results in the current study are based on a more complete characterization of this immunoreactivity. Detection of the immunoreactive species of $A \beta$ species immunoprecipitation and immunoblot (Fig. 3) indicates $A \beta$ sequence remains part of the secreted APP molecule. This observation is in contrast to $A \beta$ immunoreactivity characterized in human CSF which is due primarily, if not solely, to A $\beta$ peptide (Vigo-Pelfrey et al., 1993). Thus, the original assumption that $A \beta$ immunoreactivity in rat CSF was due solely to the A $\beta$ peptide (Seubert et al., 1992) was mistaken. This absence of $A \beta$ peptide in rat CSF indicates that one reason for the absence of plaques may be that the lesioned rat does not produce significant amounts of the $A \beta$ peptide, the pathological cleavage product of APP and precursor to the senile plaque. However, it is relevant to $\mathrm{AD}$ pathology that the rat cortex responds to neurotransmitter system lesions by secreting a form of APP which contains a significant portion of the $A \beta$ sequence. It has been demonstrated (Yankner et al., 1990) that the 1-28 fragment of $A \beta$ retains a neurotoxic activity similar to that of the complete 42 amino acid residue peptide. Thus, as suggested by Anderson et al. (1990), a protcolytic clcavage of the APP ${ }^{\mathrm{A} \beta}$ molecule could result in the generation of a neurotoxic $A \beta_{1-28}$ fragment.

In contrast, human CSF exhibits significant levels of $A \beta$ peptide (Seubert et al., 1992). The absence of $A \beta$ peptide in the lesioned rat may be due to a number of possibilities. (1) The amino acid sequence of rat APP near the proteolytic cleavage site may preclude its cleavage. (2) Rat cortex is not capable of the appropriate protease activity to produce $A \beta$. (3) The activity of protein kinase $C$ in rat cortex may be sufficient so that all of the APP is processed by the nonpathological pathway (Buxbaum et al., 1993; Hung et al., 1993). Other organisms which normally produce $A \beta$ peptide (Seubert et al., 1992) may be lesioned to determine if production of $A \beta$ is elevated under the same conditions that cause increased secretion of APP.

The same lesion conditions that exhibit induced cortical APP synthesis (Wallace et al., 1993) also exhibit elevated secretion of APP into CSF. This correlation includes the induction and secretion of APP in response to lesions of DRN, which disrupt serotonergic innervation (Fig. 5). When the time course of the nbM-induced changes were compared with DRN-induced changes, the secretion of APP and APP ${ }^{A \beta}$ was further correlated with loss of innervation. Lesions of DRN required longer times to produce maximal reductions of cortical serotonergic markers than was required for nbM lesions to maximally deplete cortical cholinergic markers. This delay was reflected in the longer time interval required for the DRN lesions to result in significantly elevated levels of APP and maximum elevations of $A P P^{A B}$ in CSF (6 weeks) compared to nbM lesions (1 week) (Fig. 6). However, one exception to this correlation was the initial reduction (at 1 hour) in secreted APP and $A P P^{A \beta}$ in CSF in response to both types of lesions (Fig. 6). APP synthesis was previously demonstrated to be maximally induced in the cortex at these same time points after nbM lesioning (Wallace et al., 1993). Thus, at the time that cortical APP synthesis is most elevated, its levels of secretion into CSF were at the lowest. The physiological importance of this reduction at this short time point after lesioning is not clear. One testable hypothesis is that secreted APP and/or APPAB are actively taken up by neurons and/or glia during this period.

Interestingly, aged animals exhibited a greater lesion-induced secretion of APP relative to younger animals (Fig. 7). Although the levels of APP mRNA were elevated to similar levels in the cortices of young versus aged rats, the induction of APP resulted in greater levels of APP in the CSF of aged animals. These observations raise the possibility of a less efficient mechanism of APP clearing in aged rats compared to young adults. This observation of elevated CSF APP is consistent with immunocytochemical results reported in aged rats (Higgins et al., 1990; Beeson et al., 1994). The correlation of CSF APP with cortical APP mRNA also supports the hypothesis that postsecretory events are responsible for the elevated levels of secreted APP in the aged rats.

In summary, elevated secretion of APP into CSF in subcortically lesioned rat brains was correlated with induction of cortical APP synthesis. This obscrvation suggests that sccretcd APP plays a role in the response of the cortex to indirect injuries such as loss of subcortical innervation, an injury of direct relevance to $\mathrm{AD}$ (Whitehouse et al., 1982). The proteolytic cleavage responsible for secretion produced a truncated form of APP that includes at least the first 28 amino acids of the $A \beta$ sequence. 
Very low levels of $A \beta$ peptide were present in CSF, consistent with the absence of senile plaques in these animals. The induction and secretion of cortical APP in response to disrupted innervation in the lesioned rat brain suggests a common pathological event may lead to both loss of specific cortical neurotransmitter systems and biogenesis of senile plaques in the Alzheimer's diseased brain.

\section{References}

Anderson JP, Chen Y, Kim KS, Robakis NK (1992) An alternative secretase cleavage produces soluble Alzheimer amyloid precursor protein containing a potentially amyloidogenic sequence. J Neurochem 59:2328-2331.

Ball M (1977) Neuronal liss, neurofibrillary tangles, and granulovacuolar degeneration in the hippocampus with aging and dementia. Acta Neuropathol 37:111-118.

Beeson J, Shelton E, Chan H, Gage F (1994) Age and damage induced changes in amyloid precursor protein immunohistochemistry in the rat brain. J Comp Neurol 342:69-77.

Buxbaum JD, Koo EH, Greengard P (1993) Protein phosphorylation inhibits production of Alzheimer amyloid $\beta / A 4$ peptide. Proc Natl Acad Sci USA 90:9165-9198.

Candy JM, Perry EK, Perry RH, Court JA, Oakley AE, Edwardson JA (1986) The current status of the cortical cholinergic system in Alzheimer's disease and Parkinson's disease. Prog Brain Res 70:105.

Chartier-Harlin MC, Crawford F, Houlden H, Warren A, Hughes D, Fidiana L, Goate A, Rossor M, Roques P, Hardy J, Mullan M (1991) Early onset Alzheimer's disease caused by mutations at codon 717 of the $\beta$-amyloid precursor protein gene. Nature 353:844-846.

Chomczynski P, Sacchi N (1987) Single step method of RNA isolation by acid guanidium thiocyanate-phenol-chloroform extraction. Anal Biochem 162:156-159.

Dekker AJ, Connor DJ, Thal LJ (1991) The role of cholinergic projections from the nucleus basalis in memory. Neurosci Biobehav Rev 15:299-317.

Esch F, Keim PS, Beattie EC, Blacher RW, Culwell AR, Oltersdorf T, McClure D, Ward PJ (1990) Cleavage of amyloid $\beta$ peptide during constitutive processing of its precursor. Science 248:1122-1124.

Fonnum $F$ (1978) A rapid radiochemical method for the determination of choline acetyltransferase. J Neurochem 24:407-408.

Goate A, Chartier-IIarlan MC, Mullan M, Brown J, Crawford F, Fidani L, Giuffra L, Haynes A, Irving N, James L, Mant R, Newton P, Rooke K, Roques P, Talbot C, Pericak-Vance M, Roses A, Williamson R, Rossor M, Owen M, Hardy J (1991) Segregation of a missense mutation in the amyloid precursor gene with familial Alzheimer's disease. Nature 349:704-706.

Golde TE, Estus S, Younkin LH, Selkoe DJ, Younkin SG (1992) Processing of the amyloid protein precursor to potentially amyloidogenic derivatives. Science 255:728-730.

Haass C, Schlossmacher MG, Hung AY, Vigo-Pelfrey C, Mellon A, Ostaszewski BL, Lieberburg I, Koo EH, Shenk D, Teplow DB, Selkoe DJ (1992) Amyloid $\beta$-peptide is produced by cultured cells during normal metabolism. Nature 359:322-325.

Hauw JJ, Duychaerts C, Dalaere P (1988) Neuropathology of aging and DAT: how can age-related changes be distinguished from those due to disease processes? Life Sci Res Rep 43:195-212.

Higgins GA, Oyler GA, Neve RL, Chen KS, Gage FH (1990) Altered levels of amyloid precursor protein transcripts in the basal forebrain of behaviorally impaired aged rats. Proc Natl Acad Sci USA 87: 3032-3036.

Hung AY, Haass C, Nitsch RM, Qiu WQ, Citron M, Wurtman RJ, Growdon JH, Selkoe DJ (1993) Activation of protein kinase C inhibits cellular production of amyloid $\beta$-protein. J Biol Chem 268: 22959-22962

Kesner RP, Adelstein T, Crutcher KA (1987) Rats with nucleus basalis magnocellularis lesions mimic mnemonic symptomology observed in patients with dementia of Alzheimer's type. Behav Neurosci 101: $451-456$.

Kesner RP, Adelstein TB, Crutcher KA (1989) Equivalent spatial location memory deficits in rats with medial septum or hippocampal formation lesions and patients with dementia of Alzheimer's type. Brain Cognit 9:289-300.

Mattson MP, Ching B, Culwell AR, Esch FS, Lieberburg I, Rydel RE
(1993) Evidence for excitoprotective and intraneuronal calcium-regulating roles for secreted forms of the $\beta$-amyloid precursor protein. Neuron 10:243-254.

Milward EA, Papadapoulos R, Fuller SJ, Moir RD, Small D, Beyreuther K, Masters CL (1992) The amyloid protein precursor of Alzheimer's disease is a mediator of the effects of nerve growth factor on neurite outgrowth. Neuron 9:129 137 .

Mirra SS, Heyman A, McKeel D, Sumi SM, Crain BJ, Brownlee LM, Vogel FS, Hughes JP, vanBelle G, Berg L (1991) The consortium to establish a registry for Alzheimer's disease (CERAD). Part II. Standardization of the neuropathologic assessment of Alzheimer's disease. Neurology 41:479-486.

Mullan M, Crawford F, Axelman K, Houlden H, Lilius L, Winblad B, Lannfeldt L (1992) A pathogenic mutation for probable Alzheimer's disease at the N-terminus of $\beta$-amyloid. Nature Genet 1:345-347.

Murrell J, Farlow M, Ghetti B, Benson MD (1991) A mutation in the amyloid precursor protein associated with hereditary Alzheimer's disease. Science 254:97-99.

Muruyama Y, Oshima T, Nakajima EI (1980) Simultaneous determination of catecholamines in rat brain by reversed-phase liquid chromatography with electrochemical detection. Life Sci 26:1115-1120.

Naruse S, Igarishi S, Kobayashi H, Aoki K, Inuzuka T, Kaneko K, Shimizu T, lihara K, Kojima T, Miyatake T, Tsuji S (1991) Missense mutation Val $\rightarrow$ Ile in exon 17 of amyloid precursor protein gene in Japanese familial Alzheimer's disease. Lancet 337:978-979.

Olton DS, Wenk GL (1987) Dementia: animal models of the cognitive impairments produced by the degeneration of the basalis forebrain cholinergic system. In: Psychopharmacology: the third generation of progress (Meltzer HY, ed), pp 941-954. New York: Raven.

Perry EK (1987) Cortical neurotransmitter chemistry in Alzheimer's disease. In: Psychopharmocology: the third generation of progress (Meltzer HY, ed), pp 887-896. New York: Raven.

Perry EK, Tomlinson BE, Blessed G, Bergmann K, Gibson PH, Perry RH (1978) Correlation of cholinergic abnormalities with senile plaques and mental test scores in senile dementia. Br Med J 2:14571459.

Quirion R, Martel JC, Robitaille Y, Etienne P, Wood P, Nair P, Gauthier $S$ (1986) Neurotransmitter and receptor deficits in senile dementia of the Alzheimer type. Can J Neurol Sci 13:503-510.

Saitoh T, Sundsmo M, Roch JM, Kimura N, Cole G, Shubert D, Oltersdorf T, Schenk DB (1989) Secreted form of amyloid $\beta$ protein precursor is involved in the growth regulation of fibroblasts. Cell 58 : 615-622.

Schmauss C, Brines ML, Lerner MR (1992) The gene encoding the small nuclcar ribonuclcoprotcin-associatcd protein $\mathrm{N}$ is expressed at high levels in neurons. J Biol Chem 267:8521-8529.

Seubert P, Vigo-Pelfrey C, Esch F, Lee M, Dovey H, Davis D, Sinha S, Schlossmacher M, Whaley J, Swindlehurst C, McCormack R, Wolfert R, Selkoe D, Lieberburg I, Schenk D (1992) Isolation and quantification of soluble Alzheimer's $\beta$-peptide from biological fluids. $\mathrm{Na}$ ture 359:325-327.

Seubert P, Oltersdorf T, Lee MG, Barbour R, Blomquist C, Davis DL, Bryant K, Fritz LC, Galasko D, Thal LJ, Lieberburg I, Schenk DB (1993) Secretion of $\beta$-amyloid precursor protein cleaved at the amino terminus of the $\beta$-amyloid peptide. Nature 361:260-263.

Shoji M, Golde TE, Ghiso J, Cheung TT, Estus S, Shaffer LM, Cai XD, McKay DM, Tinter R, Frangione B, Younkin SG (1992) Production of the Alzheimer amyloid $\beta$ protein by normal proteolytic processing. Science 258:126-129.

Smith-Swintosky VL, Pettigrew LC, Craddock SD, Culwell AR, Rydel RE, Mattson MP (1994) Secreted forms of $\beta$ amyloid precursor pro tein protect against ischemic brain injury. J Neurochem 63:781-784.

Thal LJ, Mandel RJ, Terry RD, Buzaki G, Gage FH (1990) Nucleus basalis lesions fail to induce senile plaques in the rat. Exp Neurol 108:88-90.

Vigo-Pelfrey C, Lee D, Keim P, Lieberburg I, Schenk DB (1993) Characterization of $\beta$-amyloid peptide from human cerebrospinal fluid. $J$ Neurochem 61:1965-1968.

Wallace W, Bragin V, Robakis NK, Sambamurti K, VanderPutten D, Merril CR, Davis KL, Haroutunian V (1991) Increased biosynthesis of Alzheimer amyloid precursor protein in the cerebral cortex of rats with lesions of the nucleus basalis of Meynert. Mol Brain Res 10 : 173-178. 
Wallace W, Ahlers ST, Gotlib J, Bragin V, Sugar J, Gluck R, Shea PA Davis KL, Haroutunian V (1993) Amyloid precursor protein in the cerebral cortex is rapidly and persistently induced by loss of subcortical innervation. Proc Natl Acad Sci USA 90:8712-8716.

Whitehouse PJ, Price DL, Struble RG, Clark AW, Coyle JT (1982) Alzheimer's disease and senile dementia: loss of neurons in the basal forebrain. Science 215:1237-1239.
Yankner BA, Duffy LK, Kirschner DA (1990) Neurotrophic and neurotoxic effects of amyloid $\beta$ protein: reversal by tachykinin neuropeptides. Science 250:279-282.

Yoshioka K, Miki T, Katsuya T, Ogihara T, Sakaki Y (1991) The ${ }^{717} \mathrm{Val} \rightarrow$ Ile substitution in amyloid precursor protein is associated with familial Alzheimer's disease regardless of ethnic groups. Biochem Biophys Res Commun 178:1141-1146. 